\title{
Prevalence of Selected Sexually and Blood-Borne Infections in Injecting Drug Abuser Inmates of Bandar Abbas and Roodan Correction Facilities, Iran, 2002
}

\author{
Parivash Davoodian $^{1}$, Habib Dadvand ${ }^{2}$, Khatereh Mahoori ${ }^{3}$, Alireza Amoozandeh ${ }^{1}$ and Alborz Salavati ${ }^{4}$ \\ ${ }^{1}$ Department of infectious Disease, Hormozgan University of Medical Sciences; ${ }^{2}$ Hormozgan University of Medical Sciences; ${ }^{3}$ Department of \\ Social Medicine, Hormozgan University of Medical Sciences, Hormozgan, Iran; ${ }^{4}$ Tehran University of Medical Sciences, Tehran, Iran
}

\begin{abstract}
Human Immunodeficiency Virus (HIV) and other blood borne viral infections like hepatitis B virus (HBV) and hepatitis $\mathrm{C}$ virus (HCV) are major health issues especially in young and growing population of developing countries. All around the globe correctional facilities are known as potential source of spreading such disease. During summer 2002, HIV, HCV antibodies, hepatitis B surface (HBs) antigen and rapid plasma reagin (RPR) test were checked in venous blood samples of 252 injecting drug abuser prisoners from correctional facilities in southern Iran. Overall HIV, HCV and HBV infection rate was 15.1\% (38/249), 64.8\% (163/249), and 4.7\% (12/249), respectively. HCV infection rate of HIV positive cases was $94 \%$ (35/38). All RPR results were negative. Duration of previous drug abuse and imprisonment were correlated with HIV and HCV infection (p value $=0.0003$ and $0.015 \&$ p value $=0.02$ and 0.02). Considering the higher prevalence of HIV and HCV infection in correctional facilities compared to general population of Iran, warrants immediate multidisciplinary approaches targeted at controlling further spread of these infections primarily among prisoners and secondarily preventing them to act as carrier to general population. Key-Words: HIV, Iran, prisons, HBV, HCV.
\end{abstract}

Controlling an infection needs accurate knowledge of epidemiologic attributes beside it's natural history and biological characteristics. Epidemiology of Human Immunodeficiency Virus (HIV) infection - as other blood borne viruses- in Middle East is a concerning issue in these countries. Considering the route of infection, injecting drug abuse and unprotected sexual contact are major contributors to this ongoing spread of these diseases.

Opiate narcotics are the most common profile of drug abuse in Iran. Although opium abuse has reduced in some countries in the region, yet it is the drug of choice for the majority of narcotic abusers in Iran [1]. According to the World Drug Report [2] it has been estimated that $2.8 \%$ of the adult population aged 15-64 in Iran are opiate abusers.

In the 2004 Rapid Situation Assessment (RSA) in Iran $12.2 \%$ of participants were injecting drug users (IDUs) and in this report the number of IDUs was estimated to be approximately 180,000 [3,4].

According to the RSA 2004 report from Iran, 85\% of IDUs used sterile syringe as injection device, while lifetime history of sharing injection equipment was reported more than $50 \%$ in the same report. In other studies, history of sharing injection equipment has been reported in up to $70 \%$ of IDUs [5].

HIV infection rate has been reported $15.2 \%$ and $5.4 \%$ in injecting and non-injecting drug abusers in Iran, respectively [6]. Unprotected sexual contact in this population (IDUs) is the additional cause of HIV infection. In 2005-2006, 62.3\% of HIV cases in Iran were attributed to injection drug abuse [5]. All along past decade different studies have focused on imprisonment as an important risk factor for acquiring these infections $[7,8]$ regarding high prevalence of injecting drug abuse and syringe sharing, tattooing, unprotected sexual

Received on 6 May 2009; revised 29 September 2009.

Address for correspondence: Dr. Parivash Davoodian. P.O.Box: 131851678, Tehran, Iran. Phone: +9821 66439463. Fax: +9821 66423304.

E-mail: parivashdavoodian@yahoo.com.

The Brazilian Journal of Infectious Diseases

2009;13(5):356-358. (C) 2009 by The Brazilian Journal of Infectious Diseases and Contexto Publishing. All rights reserved. contact in this population before and during the imprisonment. Early in the HIV epidemic many studies reported the prisons as a incubation dish $[7,9,10]$.

At the time of this study $64 \%$ of HIV positive cases in Iran had acquired this infection through needle sharing [11]. According to official declaration of IRI ministry of health and medical education, HIV prevalence was 15\% among injecting drug abusers (IDUs) who have visited special care and free sterile syringe dispensing facilities in southern Tehran during 2002. Another study in Hamedan was carried out in 2003 yielded HIV prevalence of $1 \%$ and HCV sero-prevalence of $39 \%$ in injecting drug user (IDU) inmates [12]. A crosssectional study in Zanjan prison in 2001 revealed an HIV prevalence of $1.2 \%$ among drug abuser inmates [13].

The aim of this study was to determine sero-prevalence of HIV, hepatitis B virus (HBV) and hepatitis C virus (HCV) in this high risk population (prisoners) in southern Iran. For this purpose, injecting drug abuser volunteers from Bandar Abbas and Roodan prisons were randomly selected and asked to participate in this study.

According to accompanying risk factors which coexist with drug abuse, such as unprotected sexual contact, syphilis serologic test, rapid plasma reagin (RPR) was also assessed in volunteers $[14,15]$.

\section{Material and Methods}

Over 250 prisoners from 1489 prisoners of Bandar Abbas and Roodan prisons in Hormozgan province in southern Iran, who according to their prison files were injecting drug users, were randomly selected by a random number generator by their file number and were informed about the purpose of the study and asked to volunteer for checking HIV, HCV, HBV and syphilis serologic blood tests. Respecting the Helsinki declaration, the sample were taken anonymously and were labeled by random numeral codes only to correlate the risk factor questionnaire to test results and all test results were treated as nameless personal medical data during the study unless the case preferred to be informed about the results in 
which a simple numeral code would have been given to the inmate to facilitate access to test results.

The study protocol was approved by research ethics committee of Hormozgan University of Medical Sciences and each patient gave informed consent before enrollment in the study.

Overall 252 IDU prisoners volunteered, and $10 \mathrm{cc}$ of peripheral venous blood was drawn form each person during June to September 2002. A questionnaire (developed by the authors themselves) was filled out in each case to obtain demographic, educational, previous imprisonment, history of drug abuse and routes of drug administration, and other known risk factors.

Sera were checked for HIV antibody, hepatitis B surface (HBs) antigen, HCV antibody, by ELISA at reference laboratory of Iran's transfusion organization in Bandar Abbas. Positive HIV results were checked by western blotting at central reference laboratory of Iran's transfusion organization in Tehran. A rapid regain test (RPR) was carried out in same settings to assess syphilis.

To facilitate detection of any correlations between duration of imprisonment or duration of drug abuse and acquiring blood-borne infections, participants were categorized according to the duration of imprisonment and drug abuse. Statistical analysis was carried out by EPI 6.0.

\section{Results}

Two hundred fifty two IDU prisoners (202 from BandarAbbas and 50 from Roodan prison) entered this cross-sectional study. Average age of participants was 35.4 years (standard deviation $=8.4$ years). About $20 \%$ of participants were illiterate and about half of them were halted at elementary school. Average duration of drug abuse and imprisonment were 79 and 33 months, respectively (Table 1).

There were 38 HIV positive cases among 249 prisoners (15.1\%). Concurrent HIV and HCV infection rate was 13.8\% $(n=36)$. HCV sero-prevalence was 163/249 (64.8\%) and HBS antigen was detected in 4.7\% (12/249) of cases. Concurrent HIV, HBV and HCV infection reported in 3 cases (1.2\%). Ninety four percent (35/38) of HIV positive cases were also HCV positive. All RPR results were negative (Table 2).

No significant correlation was detected between previous history of episodes of fever, rash or icterus and viral hepatitis. Among who had served less than a year in prison, HIV and HCV sero-positivity were $11.4 \%$ (14/122) and 56.5\% (69/122) which was less than participants serving more than a year ( $\mathrm{p}$ value $=0.0003$ and 0.015 ) (Table 3).

Hundred sixty six cases mentioned previous drug abuse of which, 31 turned out to be HIV positive (18.6\%) and 123 were $\mathrm{HCV}$ positive (74.0\%). There was a significant increase in the risk of HIV and HCV acquisition by increase of duration of drug abuse (p value $=0.02$ and 0.02 ), (Table 4).

HBS antigen positivity had no significant difference among short term and long term drug abusers, neither short nor long term prisoners.

\section{Discussion}

Overcrowding of living premises has always been an important factor in infectious contagious diseases control. Considering the globally increasing HIV infection which has
Table 1. Sociodemographic and behavioral data of prisoners.

\begin{tabular}{ccc}
\hline Duration & $\begin{array}{c}\text { Imprisonment } \\
\mathbf{n}(\mathbf{\%})\end{array}$ & $\begin{array}{c}\text { Drug abuse } \\
\mathbf{n ~ ( \% )}\end{array}$ \\
\hline$<1$ year & $39(23.5 \%)$ & $122(49.0 \%)$ \\
$1-5$ years & $58(34.9 \%)$ & $91(36.5 \%)$ \\
$6-10$ years & $38(22.9 \%)$ & $22(8.8 \%)$ \\
$>10$ years & $31(18.7 \%)$ & $14(5.6 \%)$ \\
Total & $166(100 \%)$ & $249(100 \%)$ \\
\hline
\end{tabular}

Table 2. Sero-prevalence of HIV, HBV and HCV in the study population.

\begin{tabular}{lrr}
\hline Infection & n & \% \\
\hline HBs antigen positive & 12 & $4.7 \%$ \\
HCV- Ab positive & 163 & $64.8 \%$ \\
HIV-Ab positive & 38 & $15.1 \%$ \\
Concurrent HIV \& HBV & 3 & $1.1 \%$ \\
Concurrent HIV \&HCV & 36 & $14.3 \%$ \\
HIV \& HBV \& HCV & 3 & $1.1 \%$ \\
HBV \& HCV & 7 & $2.8 \%$ \\
Syphilis (RPR) & 0 & 0
\end{tabular}

HIV: Human Immunodeficiency Virus, HCV: hepatitis C virus, HBs antigen: hepatitis B surface antigen, HBV: hepatitis B virus, RPR: rapid plasma regain.

Table 3. HIV and HCV sero-prevalence and imprisonment duration.

\begin{tabular}{ccr}
\hline $\begin{array}{c}\text { Duration of } \\
\text { imprisonment }\end{array}$ & $\begin{array}{c}\text { HIV } \\
\text { positive/total (\%) }\end{array}$ & $\begin{array}{c}\text { HCV } \\
\text { positive/total (\%) }\end{array}$ \\
\hline$<1$ & $14 / 122(11.4 \%)$ & $69 / 122(11.4 \%)$ \\
$1-5$ & $10 / 91(10.9 \%)$ & $57 / 91(10.9 \%)$ \\
$>5$ & $14 / 36(38.8 \%)$ & $31 / 36(38.8 \%)$ \\
Total & $38 / 249(100 \%)$ & $157 / 249(100 \%)$ \\
\hline
\end{tabular}

Table 4. Duration of drug abuse and viral infections.

\begin{tabular}{lcrr}
\hline $\begin{array}{l}\text { Duration of } \\
\text { drug abuse }\end{array}$ & $\begin{array}{c}\text { HIV positive } \\
\text { (n/\%) }\end{array}$ & $\begin{array}{r}\text { HCV positive } \\
\text { (n/\%) }\end{array}$ & Total (n) \\
\hline Less than a year & $3(7.6 \%)$ & $24(61.5 \%)$ & 39 \\
1 to 5 years & $8(13.7 \%)$ & $39(67.2 \%)$ & 58 \\
6 to 10 years & $10(26.3 \%)$ & $33(86.8 \%)$ & 38 \\
More than 10 & $10(32.2 \%)$ & $27(87.0 \%)$ & 31 \\
Total & $31(18.6 \%)$ & $123(74.0 \%)$ & 166 \\
\hline
\end{tabular}

reached the Middle East over a decade ago quick decision making is the key to prevent this devastating disease and accurate knowledge of the possible sources of infection is crucial. Even though the HIV transmission through sexual contact is growing in middle east and as a recent study yielded it's becoming the primary route of infection in female patients [16], due to some cultural issues it's still the second common route of HIV acquisition overall. Still the primary source are the injecting drug abusers who share needles and syringes repeatedly and the situation may aggravate in closed 
environments like prisons if not treated wisely and the fear sustains that these facilities may play a role in propagating blood-borne infections. Previous studies revealed a prevalence of 0.014 and 0.005 for HIV in general population blood donors in Iran $[17,18]$ and this study yielded a prevalence of $15.1 \%$ among prisoners using drugs intravenously. Another study in northern Iran revealed that 7\% of imprisoned IDUs were HIV positive and the rate in Zanjan prison was 1.2\% [13,19] which all reveal high concentration of this infection in prison inmates comparing to general population which implicates higher risk of acquiring such infections in these settings.

Although multiple management systems are being tested these days, still the risk of needle sharing is higher inside prisons as high as 76\% in Scotland and 60\% in Australia comparing to $24 \%$ and $20 \%$ rate out side of prison [20].

HCV infection seems to be a greater threat inside prisons as reported in Canadian correctional facilities HCV infection rate is higher than HIV [20]; Findings of this study has also shown that $64.8 \%$ IDU prisoners were $\mathrm{HCV}$ positive and $94.7 \%$ of HIV positive cases were also HCV positive which is far higher than HIV infection rate in this population that could be rationalized by higher transmissibility of $\mathrm{HCV}$ in comparison to HIV during needle sharing. Beside the untreatable and chronic nature of $\mathrm{HCV}$ infection the only possible way to control this infection is prevention, which even more clarifies the importance of sterile syringe and needle being distributed inside prisons. HCV Sero-positivity was reported as high as $47.7 \%$ and $60 \%$ in other Iranian correctional facilities $[13,19]$. Only $4.7 \%$ of cases were HBS antigen positive which not much far from the general population average of eastern Mediterranean region, how ever not assessing hepatitis B core antibody (HBc antibody) may have led to under estimating $\mathrm{HBV}$ infection in IDU prisoners.

There was no serologic evidence of syphilis infection in this study. There was no other source for comparison but may be due to vast over use of antibiotics in Iran or fortunately less unprotected sexual contact inside prisons.

There was significant correlation between duration of imprisonment and duration of parental drug abuse and odds of HIV and HCV infection.

However, Multivariate analyses were not applied in this study to remove some probable confounding factors and this is our study limitation and should be considered in future studies.

Lesser hygienic resources available at crowded places like prisons and jails and higher prevalence of formerly discussed infections in these facilities favors an infectious source which a noticeable portion of general population pass through and will act as carrier of such disease in and out of correctional facilities. Considering the low prevalence of these diseases in general population, it is necessary to take advantage of this golden time to take full strength preventive measures such as providing free sterile syringes in correctional facilities, separation of short term and long term abuser inmates, lessening the prisoner population which requires multidisciplinary approach, specially in correctional facilities of southern Iran which have higher prevalence rate of HIV and HCV infection compared to other prison in the country, to try to control the ongoing epidemic and prevent it's rapid spread.

\section{Acknowledgement}

The author would like to thank Farzan Institute for Research and Technology for technical assistance.

\section{References}

1. Mokri A., Taherinakhost H. R., Chawarski M. C., Schottenfeld, R.S. Opium dependence in Iran: A continuing habit with intriguing nature and course. Poster session presented at the 67th Annual Scientific Meeting of the College on Problems of Drug Dependence, June 18-25, 2005, Orlando.

2. United Nations Office on Drugs and Crime (UNODC). World Drug Report 2005 (UN Publication No. E.05.XI.10 ISBN 92-1148200-3). Vienna: UNODC, 2005.

3. Narenjiha H. Rapid situation assessment of drug abuse and drug dependence in Iran. Circulated report [in Persian], Darius Institute, 2005.

4. Yassami M.T. Epidemiology of Drug Abuse in I.R. Iran Unpublished manuscript [in Persian]. I.R. Iran Ministry of Health and Medical Education; Drug Control Headquarters, 2002.

5. Celentano D., Beyrer C. Public Health Aspects of HIV/AIDS in Low and Middle Income Countries: Epidemiology, Prevention and Care. Springer, Sep 12, 2008.

6. Zamani S., Kihara M., Gouya M.M., et al. Prevalence of and factors associated with HIV-1 infection among drug users visiting treatment centers in Tehran, Iran. AIDS 2005; 19:709-716.

7. Spaulding A., Stephenson B., Macalino G., et al. Human immunodeficiency virus in correctional facilities: a review. Clin Infect Dis 2002;35:305-312.

8. Stark K., Bienzle U., Vonk R., Guggenmoos-Holzmann I. History of syringe sharing in prison and risk of hepatitis B virus, hepatitis C virus, and human immunodeficiency virus infection among injecting drug users in Berlin. Int J Epidemiol 1997;26:1359-1366.

9. Wormser G.P., Krupp L.B., Hanrahan R., et al. Acquired immunodeficiency syndrome in male prisoners. Ann Intern Med 1983; 98:297-303.

10. Mutter R.C., Grimes R.M., Labarthe D. Evidence of intraprison spread of HIV infection. Arch Intern Med 1994; 154:793-795.

11. H.A.D.I. project studies. Available at: http://www.sapto.hbi.ir/ Aboutco.htm. Accessed 20 Sep 2008.

12. Alizadeh A.H., Alavian S.M., Jafari K., Yazdi N. Prevalence of hepatitis $\mathrm{C}$ virus infection and its related risk factors in drug abuser prisoners in Hamedan-Iran. World J Gastroenterol 2005;11:4085-9.

13. Khani M, Vakili MM. Prevalence and risk factors of HIV, Hepatitis $B$ virus and Hepatitis $C$ virus infections in drug addicts among Zanjan prisoners. Arch Iranian Med 2003;6:1-4.

14. Massad E., Rozman M., Azevedo R.S., et al. Seroprevalence of HIV, HCV and syphilis in Brazilian prisoners: preponderance of parenteral transmission. Eur J Epidemiol 1999;15:439-445.

15. HIV/AIDS in prisons. Canadian HIV/AIDS legal network. Canadian HIV/AIDS Policy and Law Review 2002;7; 14-22.

16. Ramezani A., Mohraz M., Gachkar L. Epidemiologic Situation of Human Immunodeficiency Virus HIV/AIDS Patients) in a Private Clinic in Tehran, Iran. Arch Iran Med 2006; 9: 315 - 318.

17. Jahromi T, et al. The frequency of HIV infection in blood donors in shiraz in 1998 - 2002. Journal of Zanjan University of Medical Sciences \& Health Services 2003; 42: 49 - 54.

18. Mahmoodian-Shooshtari M., Pourfathollah A. An Overview Analysis of Blood Donation in the Islamic Republic of Iran. Arch Iran Med 2006; 9: 200-203.

19. Rowhani Rahbar A., Tabatabaee-Yazdi A., Panahi M. Prevalence of common blood-borne infections among imprisoned injection drug users in Mashhad, North-East of Iran. Arch Iran Med 2004;7: 190-194.

20. Correctional Service Canada. Evaluation of HIV/AIDS Harm Reduction Measures in the Correctional Service of Canada. Ottawa:CSC. 1999. (http://www.hc-sc.gc.ca/ahc-asc/pubs/int-aids-sida/hiv-vih-aids-sidaprison-carceral-6-eng.php). Accessed 27 Sep 2008. 